\title{
Neuroprotective effects of Withania somnifera in BPA induced-cognitive dysfunction and oxidative stress in mice
}

\author{
Hareram Birla ${ }^{\dagger}$, Chetan Keswani ${ }^{\dagger}$, Sachchida Nand Rai, Saumitra Sen Singh, Walia Zahra, Hagera Dilnashin, \\ Aaina Singh Rathore and Surya Pratap Singh*
}

\begin{abstract}
Background: Bisphenol A (BPA), a major endocrine disruptor and a xenobiotic compound is used abundantly in the production of polycarbonate plastics and epoxy resins. Human exposure to this compound is primarily via its leaching from the protective internal epoxy resin coatings of containers into the food and beverages. In addition, the plastics used in dental prostheses and sealants also contain considerable amount of BPA and have a high risk of human exposure. Since it is a well-known endocrine disruptor and closely mimics the molecular structure of human estrogen thereby impairing learning and memory. Withania somnifera (Ws), commonly known as Ashwagandha is known for its varied therapeutic uses in Ayurvedic system of medicine. The present study was undertaken to demonstrate the impairment induced by BPA on the spatial learning, working memory and its alleviation by Ws in Swiss albino mice. The study was conducted on thirty Swiss albino mice, randomly distributed among three groups: control, BPA and $\mathrm{BPA}+$ Ws. The behavioral recovery after treatment with Ws was investigated using the Y-maize and Morris water maize test. Whereas, for the estimation of recovery of NMDA receptor which is related to learning and memory in hippocampus region by western blot and immunohistochemistry. Furthermore, the oxidative stress and antioxidant level was assessed by biochemical tests like MDA, SOD and catalase.

Results: The study revealed that administration of Ws alleviated the behavioral deficits induced by BPA. Alongside, Ws treatment reinstated the number of NMDA receptors in hippocampus region and showed anti-oxidative property while ameliorating the endogenous anti-oxidant level in the brain.
\end{abstract}

Conclusion: These findings suggest that Ws significantly ameliorates the level of BPA intoxicated oxidative stress thereby potentially treating cognitive dysfunction which acts as the primary symptom in a number of neurodegenerative diseases.

Keywords: Cognitive impairment, Neurotoxicity, Oxidative stress, Spatial memory, Reactive oxygen species, Biomarkers

\section{Background}

Bisphenol A (BPA, 4zx, 40-isopropylidene-2-diphenol) is the building block in the manufacture of polycarbonate plastics, epoxy resins, compact discs, dental sealants and thermal papers [1]. The primary source of BPA exposure in human population, worldwide is due

\footnotetext{
*Correspondence: suryasinghbhu16@gmail.com

†Hareram Birla and Chetan Keswani contributed equally to this work

Department of Biochemistry, Institute of Science, Banaras Hindu
}

University, Varanasi 221005, India to its ubiquitous presence in food and beverage packaging [2]. The different routes of BPA exposure are oral, transdermal and through inhalation [3]. Previous studies have reported the presence of alarming levels of conjugated BPA in urine, serum, umbilical cord fluid and, most hazardously in breast milk $[4,5]$. BPA has been identified as a causative agent for various perilous disorders such as cancer, thyroid deformities, cognitive impairments and male infertility as a result of its xenoestrogenic activity [6]. The surrounding 
environment has a major impact on health of the population consequently, the environmental exposure of endocrine disrupting chemicals cannot be ignored. The primary factor for cognitive impairment is ageing but there are various associated factors including the exposure of various toxins, pesticides, head injury, along with genetic predisposition [7]. BPA has been reported to cross the blood-brain barrier in different concentrations leading to various behavioral changes associated with cognitive impairment along with increased aggression, hyper-reactivity learning deficits, and increased drug dependency [8]. $\mathrm{N}$-methylD-aspartate-receptors (NMDARs), a specific kind of ionotropic glutamate receptor found in the hippocampal region of the mid brain are crucial in controlling the synaptic plasticity and cognition [9]. The hippocampus is the main site for learning and memory. BPA has been reported to decrease the expression of the subunits of NMDAR along with estrogen receptor in the hippocampus [10].

In the past decade, researchers have been determined to investigate the role of Withania somnifera (Ws), a revered Indian Ayurvedic herb commonly known as Indian Ginseng or Indian Winter Cherry, for its medicinal properties [11-13]. Studies have evaluated the medicinal properties of Ws extracts in various diseases and have established the cognition promoting effects [13, 14], anxiolytic activity [15] and neuroprotective effects [16]. Studies have made it evident that Ws root extract not only significantly lowers lipid peroxidation but also augments superoxide dismutase (SOD) and catalase activities, thereby modulating the oxidative network in the cytosol [17]. Moreover, Ws has been documented to be an effective anti-stress, anti-inflammatory, and anti-aging medicinal herb [18].

The present study is based on assessing the effect of BPA in swiss albino mice and the effect of the treatment therapy of the root extract of Ws. Our aim was to investigate the neuroprotective role of Ws in memory enhancement after damage through BPA induced cognitive dysfunction in mice.

\section{Materials and methods}

\section{Chemicals required}

Acetic acid, disodium hydrogen phosphate, nicotinamide adenine dinucleotide reduced form (NADH), potassium chloride, phenazinemethosulphate, nitro-blue tetrazolium, disodium phosphate and sodium dihydrogen phosphates were procured from Sisco Research Laboratories (Mumbai, India). Reagents for Bradford assay were purchased from GeNei (Bengaluru, India). Hydrogen peroxide and potassium-dichromate were purchased from
Merck (Darmstadt, Germany). Sodium dodecyl sulphate (SDS), thiobarbituric acid (TBA), trireagent, and zinc sulphate were procured from Sigma-Aldrich (St. Louis, MO, USA). Rabbit polyclonal to NMDAR2A (ab16646) antibody were procured from Abcam (place), mouse monoclonal anti- $\beta$-actin (sc47778) purchased from Santacruz (USA), biotinylated Goat polyclonal to Rabbit IgG and anti-mouse secondary antibodies, anti-goat AP conjugated and bovine anti-rabbit (AP) conjugated secondary antibodies were acquired from Santa Cruz Biotechnology (Santa Cruz, CA, USA). DABCO, anti-fading agent was purchased from Fluka analytical (Shanghai, China). Secondary antibody, GT $\times$ Rb IgG-Biotin conjugated $(62111028001 \mathrm{~A})$ and $\mathrm{GT} \times \mathrm{Ms}$ IgG Biotin-conjugated (cat\#105261) (GeNei, Bengaluru, India). Streptavidinperoxidase, normal goat serum and DAB system was procured from Genei Pvt. India Ltd. Polyvinylidene difloride (PVDF) membranes were procured from Merck Millipore (USA).

\section{Medicinal plants and preparation of extracts}

The plants of $W$. somnifera were procured from the Institute of Medical Science, Banaras Hindu University, Varanasi, India. Primarily, the roots of Ws were desiccated and crushed. About $600 \mathrm{~g}$ prepared powder of the Ws root was soaked overnight in $1000 \mathrm{~mL}$ ethanol and refluxed using a soxhlet apparatus. Further, the extract was concentrated under reduced pressure and stored at $4{ }^{\circ} \mathrm{C}$. Subsequently, the prepared extract was firstly filtered using filter paper (Whatman No. 1) and later dried through evaporation in rotary vacuum evaporator under reduced pressure and temperature (below $40{ }^{\circ} \mathrm{C}$ ). For in vivo assays, the extract was suspended in $0.7 \%$ carboxy methyl cellulose (CMC, S.D fine chemicals, India).

\section{Animal dosing}

The experiments performed on animals in the laboratory were as per the norms of Institutional Ethics Committee. Male Swiss albino mice weighing $25 \pm 5 \mathrm{~g}$ required for the experiments were provided by animal house of the Institute of Medical Science, Banaras Hindu University, Varanasi, India. The animals were kept in clean polypropylene cages in a maintained environment of temperature $\left(22 \pm 5{ }^{\circ} \mathrm{C}\right)$, humidity $(45-55 \%)$ and $12 \mathrm{~h}$ light-dark cycle with proper access to the standard diet of mice pellet and water. Post acclimatization, they were separated into three groups, each group with ten mice. Group-I served as control with vehicle administration. Group-II was administered with BPA $50 \mu \mathrm{g} / \mathrm{kg}$ bw/day for 21 days. Group-III was intoxicated with BPA with given Ws root extract treatment $(100 \mathrm{mg} / \mathrm{kg}$ bw/day, orally). Mice were 


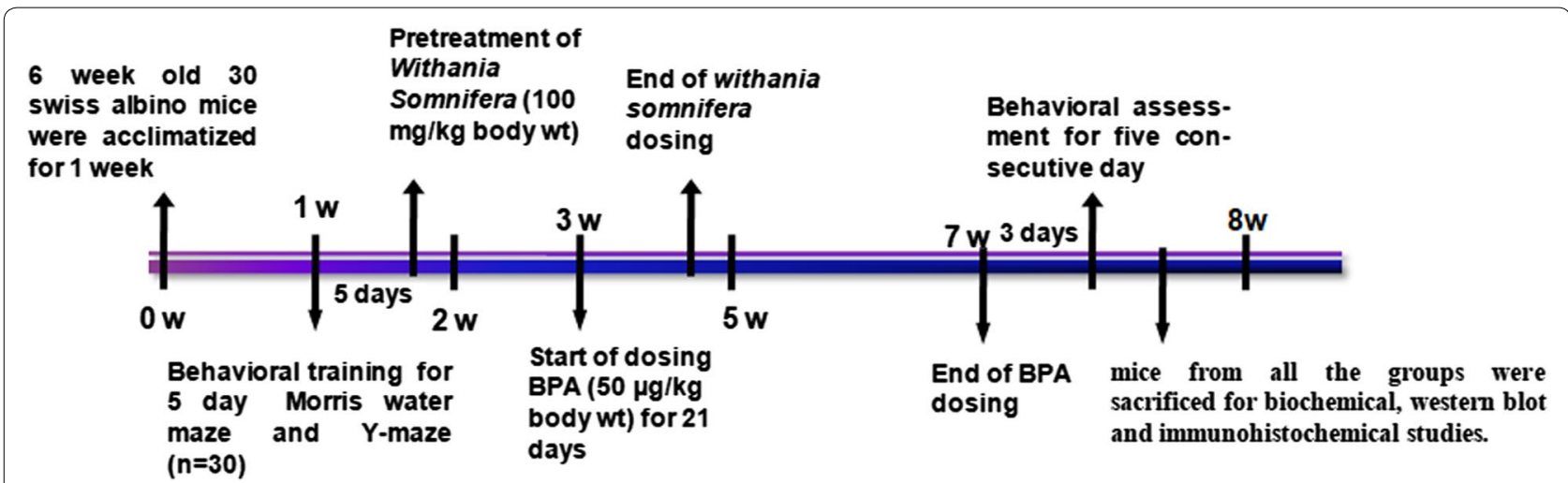

Fig. 1 Research design and testing time scale. Time scale of complete experimental procedure

pre-treated with Ws for 1 week. After the completion of dosing, mice were subjected to various tests to analyze their behavioral performance and later sacrificed for further tests (Fig. 1).

\section{Y-maze test}

Y-maze is a spontaneous alternation behavioural test, used to assess behavioural tasks in preclinical study. It is based on the willingness of rodents for exploration of a completely new environment to understand their spatial learning and memory. The analysis occurs in a Y-shaped maze with three identical black arms $(35 \times 5 \times 15 \mathrm{~cm})$ at a $120^{\circ}$ angle from each other. The mouse is put in the centre of the maze and allowed free access to all the three arms. Three trials were performed for each mouse where the test animal was placed in one of the three arms and allowed to move freely for $5 \mathrm{~min}$ in the direction of any arm. Every time a mouse chose an altered arm than the one it was placed on, it was termed as alteration and the number of these arm entries and alterations were recorded to calculate the percentage of alteration [19].

\section{Morris water maze test}

The Morris water maze (MWM) behavioral procedure was established and standardized for evaluating the spatial learning of rodents. The basic structure of the MWM test involves a large circular black painted pool $\left(100 \mathrm{~cm}^{2}\right.$ in diameter and $55 \mathrm{~cm}$ in height) filled with water to a depth of $26 \mathrm{~cm}\left(23-25^{\circ} \mathrm{C}\right)$. It is made as featureless as possible from inside. A target made of flexi-glass was submerged all through the experiment at fixed quadrant below $1 \mathrm{~cm}$ water level. The maze was divided into four equal quadrants ( $\mathrm{E}, \mathrm{W}, \mathrm{N}, \mathrm{S})$. The test was always conducted at fixed time to avoid the effect of diurnal variation. The test for analyzing the effect of BPA in mice model was carried out for 5 consecutive days with two tests per day. Maximum latency time was set as $60 \mathrm{~s}$. In case, the mouse was unable to locate the platform for a minute, it was directed towards the platform leaving it to rest for $15 \mathrm{~s}$. On 7th day, a probe test was conducted by removing the platform and the time spent in the target quadrant was duly recorded. The escape latency time during test and time spent in target quadrant during probe trial for each mouse was analyzed [20-22].

\section{Biochemical analysis \\ Lipid peroxidation}

Sample collection after the completion of behavioural tests, mice were euthanized and sacrificed by dislocation followed by decapitation to ensure minimum pain. The brain was removed and frozen immediately. Brain was dissected in ice cold conditions to isolate nigrostriatal tissue and it was stored at $80{ }^{\circ} \mathrm{C}$ until the biochemical analysis was performed. Level of lipid peroxidation was evaluated in accordance with standardized protocol with slight modifications in the hippocampus tissue of mice brain [23]. Furthermore, 10\% of homogenate was taken and added with $10 \%$ SDS solution along with $20 \%$ acetic acid. Ultimately, $0.8 \%$ TBA was mixed and the final mixture was incubated in hot water $\left(60^{\circ} \mathrm{C}\right)$ bath for $60 \mathrm{~min}$. Later, the mixture was cooled down and centrifuged. The supernatant was analyzed for absorbance at $532 \mathrm{~nm}$ with respect to control. Level of LPO was recorded in nmoles of $\mathrm{MDA} / \mathrm{mg}$ protein.

\section{Catalase and superoxide dismutase (SOD) activity}

Rate of decomposition of hydrogen peroxide was evaluated through catalase activity using spectrophotometer [24]. Further, potassium dichromate and acetic acid (1:3) were added to the homogenized tissue and incubated in hot water bath $\left(60{ }^{\circ} \mathrm{C}\right)$ for $10 \mathrm{~min}$ and absorbance was measured at $570 \mathrm{~nm}$. The enzymatic activity 
was measured in moles/min/mg protein. While, for SOD assay, NADH was used as the substrate [25]. Absorbance was observed at $560 \mathrm{~nm}$ for both the tubes with reference to the blank. Absorbance of both the blank and test sample was compared to analyze the inhibition of Nitro blue tetrazolium chloride (NBT) reduction. This was also used for protein estimation. SOD can be defined as the amount of enzyme required for the inhibition of $50 \%$ NBT reduction at $560 \mathrm{~nm}$ in $1 \mathrm{~min}$. SOD activity was expressed as unit/mg protein.

\section{Immunoblotting analysis}

The hippocampus of male mice were used to prepare $5 \%$ homogenate in RIPA buffer $[1 \times$ TBS, $1 \%$ nonyl phenoxypolyethoxylethanol- $40,0.1 \%$ sodium dodecyl sulfate, $0.6 \%$ sodium deoxycholate, $100 \mu \mathrm{g} / \mathrm{ml}$ phenylmethanesulfonyl fluoride and $5 \mu \mathrm{l} / 100 \mathrm{mg}$ protease inhibitor cocktail]. Homogenate of the sample was prepared through centrifugation which was done at $12,000 \mathrm{rpm}$ at $4{ }^{\circ} \mathrm{C}$ for about $15 \mathrm{~min}$. The supernatant thus obtained was kept at $-20{ }^{\circ} \mathrm{C}$ for further use. From the homogenate, the amount of protein was assessed through Bradford method [26]. $35 \mu \mathrm{g}$ of protein was taken, denatured and resolved in 10\% Tris-glycine SDS-PAGE which was later transferred onto the nitrocellulose membrane (Millipore, USA). Blocking of the membrane was done for about $2 \mathrm{~h}$ with $7 \%(\mathrm{w} / \mathrm{v})$ non-fat milk prepared in $1 \times \mathrm{TBS}$ at room temperature. The blot was then incubated with primary antibodies (goat anti-NMDA, 1:1000; goat anti- $\beta$-actin, 1:500 at $4{ }^{\circ} \mathrm{C}$ ) overnight. Washing was done thrice for 10 min each in $0.1 \%$ TBST ( $0.1 \%$ Tween-20 in $1 \times$ TBS) and was further incubated with secondary antibodies $(\mathrm{GT} \times \mathrm{Rb}$ IgG-Biotin conjugated $(62111028001 \mathrm{~A})$ followed by washing thrice for 5 min each in $0.1 \%$ TBST and developed by DAB method [27, 28].

\section{Immunohistochemistry}

Anesthesia was given to the mice of each group using diethyl ether and intracardial perfusion was done by injecting chilled $0.9 \%$ saline and $4 \%$ para-formaldehyde, made in $0.1 \mathrm{M}$ phosphate buffered saline (PBS) of $\mathrm{pH}$ 7.4. After decapitation, the brains were isolated and stored in 10\% para-formaldehyde for overnight and were transferred to $10 \%, 20 \%$ and $30 \%$ sucrose solutions, respectively. Using a cryomicrotome (Leica, Wetzlar, Germany), $20 \mu \mathrm{m}$ thick coronal sections of hippocampus was cut. Then, immunohistochemistry of NMDA was done in hippocampus using the standard procedure with slight modifications [29, 30]. DABCO was used as the mounting media. By using Nikon fluorescent microscope (Thermo Fisher Scientific), the images were taken and by using Image J software (NIH, United States) the immunofluorescence was evaluated. The results were reported as \% area value in hippocampus region of brain.

\section{Statistical analysis}

By applying one-way analysis of variance (ANOVA) using Student-Newman-Keuls test in the graph pad prism 5.0, all the data were analyzed. Report of the values was done as mean \pm SEM and $p$ values $<0.05$ were well thought-out as statistically significant. A repeated measures ANOVA was performed for MWM escape latency analysis and Y-maze.

\section{Results}

In the Y-maze test, spontaneous alternation and arm entries of all mice were observed (above six entries within 5 min). The BPA mice group had a lesser total number of spontaneous alteration $(\mathrm{p}<0.001)$ (Fig. 2a) and entries in arms $(\mathrm{p}<0.001)$ (Fig. 2a), as compared to the control group. But in case Ws treatment both spontaneous alteration $(\mathrm{p}<0.05)$ (Fig. 2a) and entries in arms $(\mathrm{p}<0.001)$ (Fig. 2b) were greater than BPA intoxicated mice and Ws treated mice indicating greater alteration and exploratory locomotion. Thereby, suggesting impairment of BPA intoxicated mice in the measure of short term spatial memory.

\section{Morris water maze test}

In MWM test, BPA exposed mice took longer time to reach the hidden platform as compared to that of control $(\mathrm{p}<0.001)$ (Fig. 2c). While, the time taken by the Ws administered BPA mice group was considerably lesser as compared to the BPA-intoxicated $(\mathrm{p}<0.01)$ group. After removing the platform at the end of experiment, it was observed through subsequent probe test that the BPAtreated group spent lesser time in the target quadrant and more time in other quadrants when compared to the control group and Ws group, respectively. Thus, the data obtained clearly indicated that exposure to BPA significantly impaired the spatial memory of mice while, Ws treatment improved it.

\section{Ws forestalls BPA induced oxidative stress and balances anti-oxidant levels}

Lipid-peroxidation level was assessed by analyzing the level of MDA and the effect of Ws on it was assessed in hippocampus (Fig. 3a). MDA level was found to be considerably increased in BPA-exposed impaired mice as compared to the control group in hippocampus region of brain $(\mathrm{p}<0.01)$ (Fig. 3a). The treatment with Ws on the other hand decreased the MDA level in the BPA group (Fig. 3a). The reactive oxygen species (ROS) produced in the hippocampus was also efficiently scavenged by the anti-oxidative enzymes such as SOD and catalase. In our result, Ws was found to modulate the activity of 

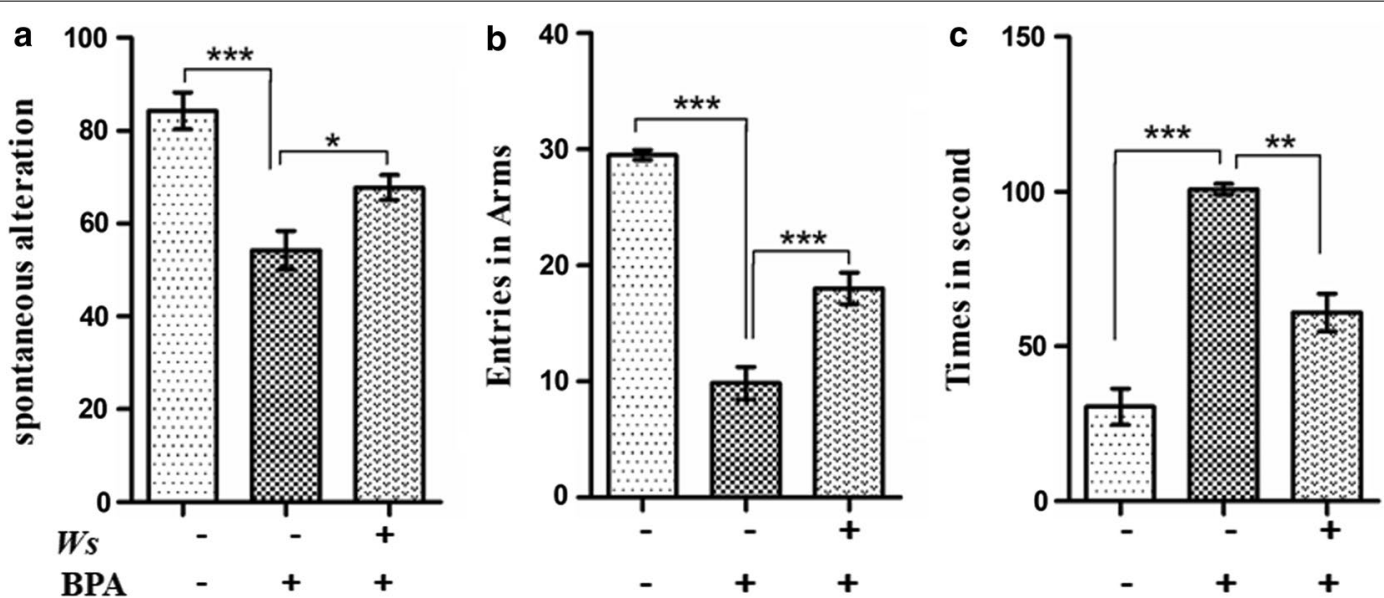

Fig. 2 Effect of BPA and BPA+Ws on spatio-temporal memory. a Spontaneous alteration. $\mathbf{b}$ Entries in Arms and Morris water maze test to reach the hidden platform. $\mathbf{c}$ Escape latency (in seconds). Data is expressed in terms of mean \pm SEM $(n=10) .\left({ }^{*} p<0.05,{ }^{* *} p<0.01,{ }^{* * *} p<0.001\right)$. SEM: standard error of mean; CONT: control; Ws: Withania somnifera; BPA: bisphenol A; SEM: standard error of mean
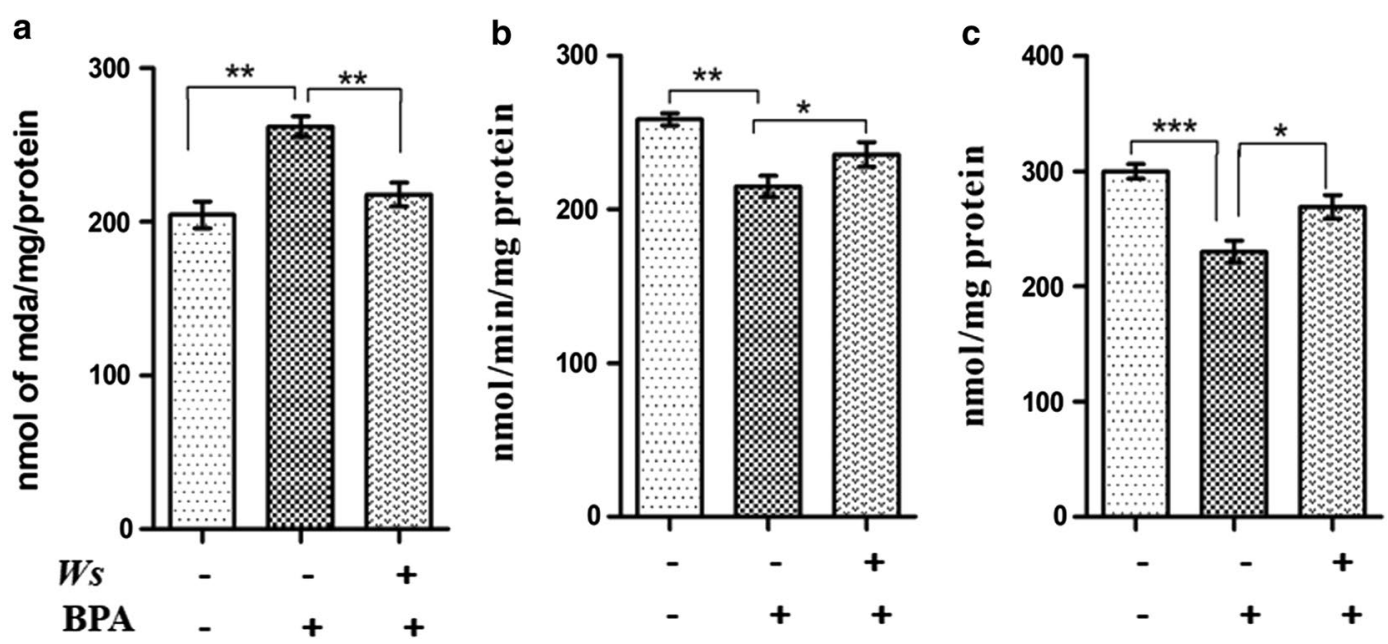

Fig. 3 Biochemical estimation of oxidative stress markers in the Hippocampus region of mice brain. a MDA, b CAT, c SOD. Values are expressed as mean $\pm \operatorname{SEM}(n=6)\left({ }^{*} p<0.05,{ }^{* *} p<0.01,{ }^{* * *} p<0.001\right)$. MDA: malondialdehyde; SOD: superoxide dismutase; CAT: catalase; SEM: standard error of mean

antioxidant enzymes. The catalase level was significantly reduced $(\mathrm{p}<0.01)$ in BPA group as compared to control group within hippocampus (Fig. 3b). Interestingly, Ws was found to significantly restore the levels of catalase in BPA intoxicated mice $(\mathrm{p}<0.05)$ (Fig. 3b). While, in the case of BPA-exposed mice, activity of SOD was found to be significantly decreased $(\mathrm{p}<0.001)$ as compared with that of control group (Fig. 3c). However, on Ws treatment, the activity of SOD was seen to be significantly elevated in comparison to BPA-exposed mice $\mathrm{p}<0.05$ (Fig. 3c).

\section{Western blot analysis of NMDA receptor}

After assessing the behavioural and biochemical parameters, the expression levels of NMDAR (147 kDa), (Fig. 4) were estimated using Western blots in tissue lysates isolated from hippocampus region. A reduced expression of NMDAR $(\mathrm{p}<0.001)$ was observed in BPA-intoxicated mice as compared to the control group. In Ws treatment group increased NMDA level $(\mathrm{p}<0.01)$ was observed when compared to BPA-intoxicated mice. 


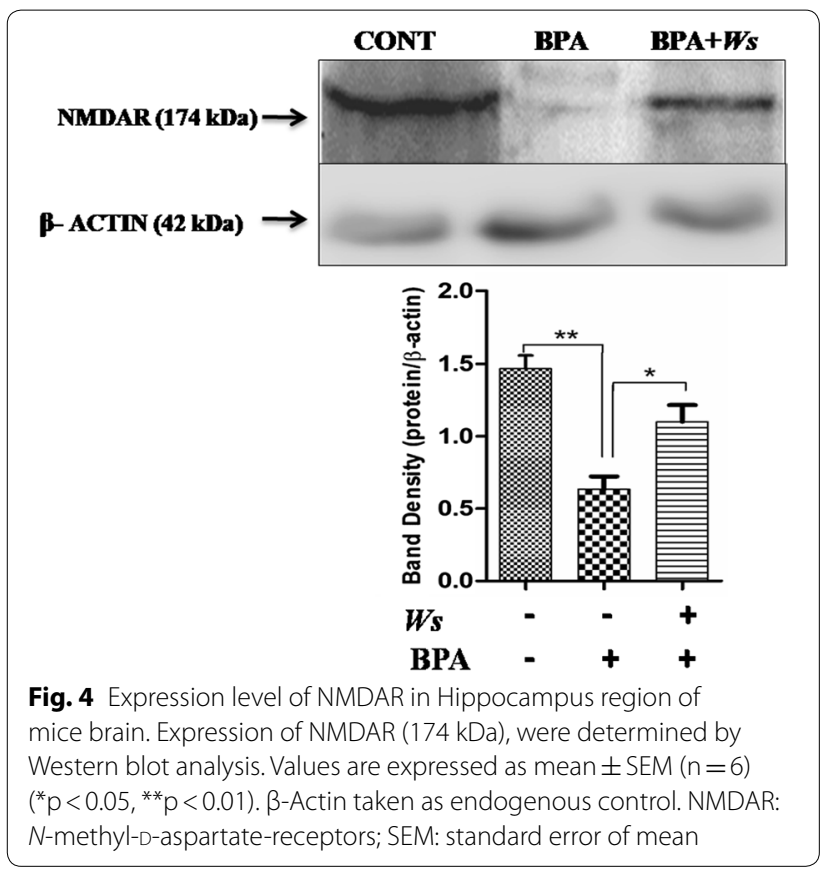

\section{Immunohistochemistry of NMDA receptor}

BPA administration resulted in significant loss of NMDA receptor $(\mathrm{p}<0.01)$ neurons in Hippocampus as compared to normal saline treated control mice (Fig. 5). The treatment of Ws to BPA group, showed significant increase of NMDAR $(\mathrm{p}<0.05)$ in comparison to BPA intoxicated mice.

\section{Discussion}

The effect of BPA $50 \mu \mathrm{g} / \mathrm{kg}$ bw/day only and in combination with Ws (100 mg/kg bw/day) was investigated on the cognition of mice. Here we hypothesized to explore the neurotoxic effects of BPA on cognitive impairment and memory dysfunction and its alleviation using Ws root extract. BPA intoxication was found to severely damage the main site for learning and memory, i.e., hippocampus.

The use of Ws extract in treating several diseases is documented from the very beginning in Ayurveda, the Indian system of medicine [31]. It has been demonstrated that the antioxidant property of herbal medicines have a substantial role in curing neurodegenerative diseases [16, 32]. Withaferin $\mathrm{A}$ is the major bioactive compound present in Ws [33]. These naturally occurring compounds have the property to enhance the regeneration of neurons by enhancing the growth of axons and dendrites $[34,35]$. The Ws extract has also been found to be effective against brain aging, beneficial for mental health and prevents motor impairment [36]. Withaferin A, has been reported to cure a number of neurological disorders [3741], though very few studies have focused on the toxicity of Ws and Withaferin A. The LD50 value of $2000 \mathrm{mg} / \mathrm{kg}$ body wt for Ws root extract containing 4.5\% Withaferin A and the safe dose has been reported upto $200 \mathrm{mg} / \mathrm{kg}$ body wt $[42,43]$.

The widely known endocrine disruptor, bisphenol A is found to be released by different polycarbonate plastics and food packaging [44]. Because of the huge availability of the toxicant in the environment, humans get frequently exposed to it on daily basis [2]. Interestingly, BPA has been found to increase oxidative stress in different regions of brain, thus the fact potentiates the role of BPA in various neurodegenerative disorders [45-47]. In rodents too, BPA is found to impair the cognition [48]. Experimentally, it has been proven that perinatal exposure of BPA interferes with the process of sexual differentiation and affects the behaviour of the newly-born animals [49]. Accordingly, Xu et al. [50] suggested that

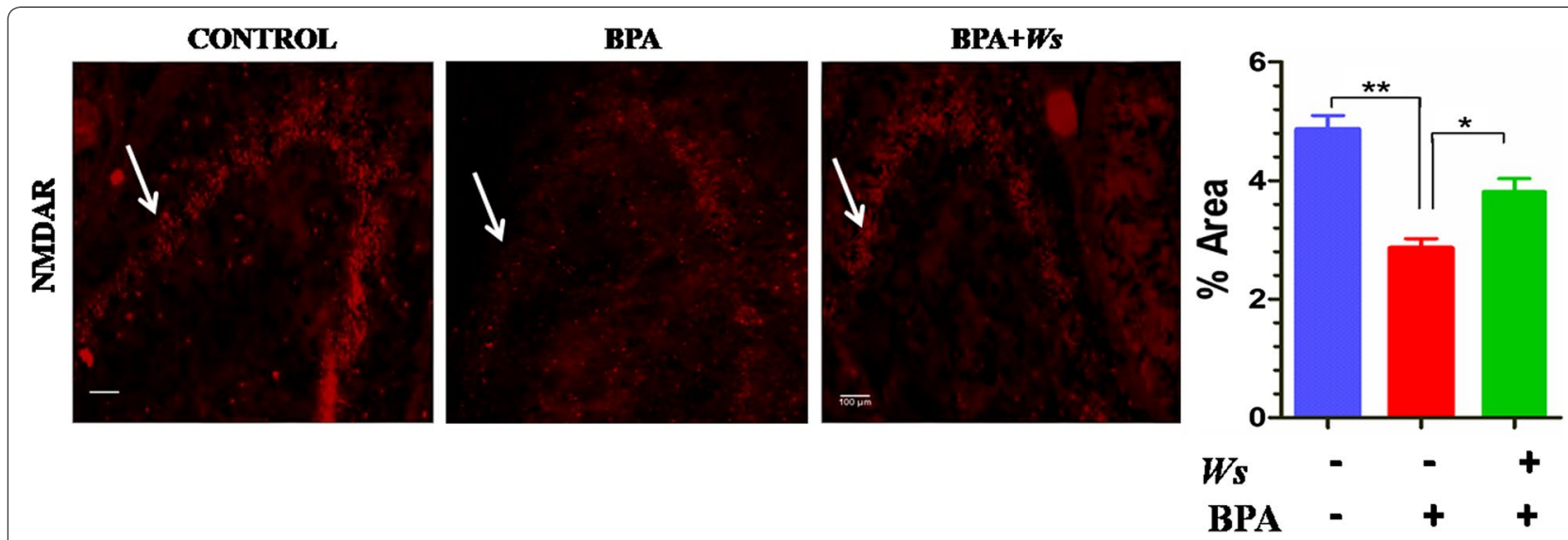

Fig. 5 IHC-IF staining of NMDAR. With $20 \times$ magnifications after staining. Expression of NMDAR in Hippocampus of mice brain. Value expressed as mean \pm SEM $(n=5)\left({ }^{*} p<0.05,{ }^{* *} p<0.01\right)$ 
on perinatal exposure to BPA, both spatial and avoidance memory were affected, subsequently influencing the normal behavioural development from neonatal to adulthood. In the current study, the results indicate that intoxication of BPA for 21 days significantly impaired the cognitive function and increased the time to reach the platform in spatial navigation task when compared to the control group in Morris water maize test. However, when the administration of Ws was done, the learning and memory was found to be significantly enhanced. We also performed Y-maze test to study the willingness of rodents towards exploring the new environments was done using Y-maze spontaneous alternation test [51]. Generally, the animals like to visit the newer arm of the maze rather than wandering into the previous one. In our study, the level of alteration and the entries in the newer arm, both were concomitantly reduced by BPA intoxication, while it considerably enhanced on treatment of Ws in the BPA-intoxicated mice.

The cognitive impairment was seen to be linked with the hippocampal down-regulation of NMDA receptor $[10,52,53]$. In this regard, our result also demonstrated that BPA intoxication leads to decreased expression of NMDA receptor. Whereas, Ws administration is capable of restoring the level of NMDAR in BPA intoxicated mice. Moreover, the Ws extract was also effective in enhancing the learning and memory in BPA intoxicated mice.

Oxidative stress has been closely associated with the pathophysiology of various diseases such as aging, atherosclerosis, diabetes, cancer and other degenerative disorders $[54,55]$. The endogenous anti-oxidant enzymes like catalase, SOD and other molecules are efficient in scavenging the amplified ROS generated in brain and other tissues [56]. Thus, the involvement of oxidative stress in BPA induced cognitive impairment was assessed using various parameters like catalase, SOD and LPO in the hippocampal region of mice. Increased level of MDA, which subsequently marks increased LPO level, was observed in the hippocampus of BPA intoxicated mice as compared to control. This result was in accordance with various studies which demonstrated that on the exposure of BPA, there is an increased generation of ROS in the brain, decreased endogenous antioxidants in the liver and the epididymal sperm [57-59]. Furthermore, Aydogan et al. [60] also suggested that enhanced level of MDA in the brain was observed upon exposure to BPA. In the present study, significant impairment in learning and memory was observed in BPA intoxicated mice in comparison to the control. Hence, this fact can be put forward that sustained oxidative stress is one of the possible phenomena responsible for cognitive impairment in BPA administered mice group. Antioxidants play a major role in preventing the progression of degenerative diseases by alleviating the oxidative stress [16]. Researchers have suggested the alteration in the redox potential in experimental animals upon contamination with the environmental insults [61]. Various reports have suggested the neuroprotective effects of Ws through its antioxidant nature in the brain [62-64]. The ethanolic extract of the roots of Ws in our study was seen to significantly reduce the level of LPO and increase the activities of SOD and catalase through its free radical scavenging activity. Thus, Ws acts as a potent anti-oxidant, regulating the level of endogenous antioxidants, which are usually depleted as a result of aggravated oxidative stress. Furthermore, it has been seen to provide protection against oxidative damage and memory impairment induced by BPA.

\section{Conclusion}

Dementia and cognitive impairment has been seen to severely affect the quality of life and life span of elderly and are the primary symptoms of neurodegenerative disorders. Moreover, oxidative stress plays an essential role in the pathogenesis of these diseases and is linked to cognitive impairment. BPA is a potent endocrine disruptor and is seen to induce the cognitive impairment. The present study deals with the neuroprotective activity of Ws against BPA-induced oxidative stress and memory impairment in mice. Therefore, our study put-forward Ws as potent drug candidate for BPA-induced cognitive impairment.

\section{Abbreviations \\ SOD: superoxide dismutase; MDA: malondialdehyde; BPA: bisphenol A; Ws: Withania somnifera; NMDAR: N-methyl-D-aspartate-receptor; MWM: Morris water maze \\ Acknowledgements \\ Authors HB, SNR, SSS, and WZ were sincerely thankful to DBT, ICMR, ICMR, CSIR-UGC, UGC India for their respective fellowships. CK and SPS are thankful to ICAR-NASF, New Delhi, India for financial support. Authors are also thank- ful to the Head, Department of Biochemistry, B.H.U for providing the basic Departmental Facility and I.S.L.S, B.H.U for their central facility.}

\section{Authors' contributions}

HB planed study, performed the experiments and analyzed data. SPS supervised the experiments as well as the manuscript preparation. HB, CK and SPS wrote the paper. SNR, WZ, SSS, ASR and HD help in animal dosing, behavioural study and manuscript preparation. All authors read and approved the final manuscript.

\section{Funding}

The study is not supported by any grant.

Availability of data and materials

The datasets used and/or analyzed during the current study are available from the corresponding author on reasonable request.

Ethics approval and consent to participate

The experiments performed on animals as per the norms of Institutional Ethics Committee, BHU, India. 


\section{Consent for publication \\ Not applicable.}

\section{Competing interests}

The authors declare that they have no competing interests.

Received: 30 January 2019 Accepted: 26 April 2019

Published online: 07 May 2019

\section{References}

1. Fromme H, Küchler T, Otto T, Pilz K, Müller J, Wenzel A. Occurrence of phthalates and bisphenol $\mathrm{A}$ and $\mathrm{F}$ in the environment. Water Res. 2002;36(6):1429-38.

2. Vandenberg LN, Hauser R, Marcus M, Olea N, Welshons WV. Human exposure to bisphenol A (BPA). Reprod Toxicol. 2007;24(2):139-77.

3. Geens T, Aerts D, Berthot C, Bourguignon J-P, Goeyens L, Lecomte P, et al. A review of dietary and non-dietary exposure to bisphenol-A. Food Chem Toxicol. 2012:50(10):3725-40.

4. Rochester JR, Bolden AL. Bisphenol S and F: a systematic review and comparison of the hormonal activity of bisphenol A substitutes. Environ Health Perspect. 2015;123(7):643-50.

5. Ribeiro E, Ladeira C, Viegas S. Occupational exposure to bisphenol A (BPA): a reality that still needs to be unveiled. Toxics. 2017;5(3):22.

6. Kawato $S$. Endocrine disrupters as disrupters of brain function: a neurosteroid viewpoint. Environ Sci. 2004;11(1):1-14.

7. Chin-Chan M, Navarro-Yepes J, Quintanilla-Vega B. Environmental pollutants as risk factors for neurodegenerative disorders: Alzheimer and Parkinson diseases. Front Cell Neurosci. 2015;9:124.

8. Inadera H. Neurological effects of bisphenol A and its analogues. Int Med Sci. 2015;12(12):926.

9. Gilmour G, Dix S, Fellini L, Gastambide F, Plath N, Steckler T, et al. NMDA receptors, cognition and schizophrenia-testing the validity of the NMDA receptor hypofunction hypothesis. Neuropharmacology. 2012;62(3):1401-12

10. Xu X, Li T, Luo Q, Hong X, Xie L, Tian D. Bisphenol-A rapidly enhanced passive avoidance memory and phosphorylation of NMDA receptor subunits in hippocampus of young rats. Toxicol Appl Pharmacol. 2011:255(2):221-8.

11. Dar PA, Singh LR, Kamal MA, Dar TA. Unique medicinal properties of Withania somnifera: phytochemical constituents and protein component. Curr Pharm Des. 2016;22(5):535-40.

12. Keswani $C$, Bisen $K$, Singh $S$, Singh $H$. Traditional knowledge and medicinal plants of India in intellectual property landscape. Med Plants Int J Phytomed Relat Ind. 2017:9(1):1-11.

13. Baitharu I, Jain V, Deep SN, Hota KB, Hota SK, Prasad D, et al. Withania somnifera root extract ameliorates hypobaric hypoxia induced memory impairment in rats. J Ethnopharmacol. 2013;145(2):431-41 (PubMed PMID: 23211660. Epub 2012/12/06. eng).

14. Choudhary D, Bhattacharyya S, Bose S. Efficacy and safety of Ashwagandha (Withania somnifera (L.) Dunal) root extract in improving memory and cognitive functions. J Diet Suppl. 2017;14(6):599-612.

15. Verma SK, Kumar A. Therapeutic uses of Withania somnifera (Ashwagandha) with a note on with anolides and its pharmacological actions. Asian J Pharm Clin Res. 2011;4(1):1-4.

16. Prakash J, Yadav SK, Chouhan S, Singh SP. Neuroprotective role of Withania somnifera root extract in Maneb-Paraquat induced mouse model of parkinsonism. Neurochem Res. 2013:38(5):972-80.

17. Bhattacharya A, Ghosal S, Bhattacharya S. Anti-oxidant effect of Withania somnifera glycowithanolides in chronic footshock stress-induced perturbations of oxidative free radical scavenging enzymes and lipid peroxidation in rat frontal cortex and striatum. J Ethnopharmacol. 2001;74(1):1-6.

18. Schliebs R, Liebmann A, Bhattacharya SK, Kumar A, Ghosal S, Bigl V. Systemic administration of defined extracts from Withania somnifera (Indian Ginseng) and Shilajit differentially affects cholinergic but not glutamatergic and GABAergic markers in rat brain. Neurochem Int. 1997:30(2):181-90.

19. King DL, Arendash GW. Behavioral characterization of the Tg2576 transgenic model of Alzheimer's disease through 19 months. Physiol Behav. 2002;75(5):627-42.
20. Kumar D, Thakur MK. Perinatal exposure to bisphenol-A impairs spatial memory through upregulation of neurexin 1 and neuroligin3 expression in male mouse brain. PLOS ONE. 2014:9(10):e110482.

21. Yadav SK, Pandey S, Singh B. Role of estrogen and levodopa in 1-methyl4-pheny-I-1, 2, 3, 6-tetrahydropyridine (mptp)-induced cognitive deficit in Parkinsonian ovariectomized mice model: a comparative study. J Chem Neuroanat. 2017:85:50-9.

22. Prabhu W, Nguyen TB, Cui Y, Oh Y-E, Lee K-H, Bagalkot TR, et al. Effects of social defeat stress on dopamine D2 receptor isoforms and proteins involved in intracellular trafficking. Behav Brain Funct. 2018;14(1):16.

23. Rai SN, Birla H, Singh SS, Zahra W, Patil RR, Jadhav JP, et al. Mucuna pruriens protects against MPTP Intoxicated neuroinflammation in Parkinson's disease through NF-kB/pAKT signaling pathways. Front Aging Neurosci. 2017:9:421.

24. Kumar A, Prakash A, Dogra S. Naringin alleviates cognitive impairment, mitochondrial dysfunction and oxidative stress induced by D-galactose in mice. Food Chem Toxicol. 2010;48(2):626-32.

25. McCord JM, Fridovich I. Superoxide dismutase an enzymic function for erythrocuprein (hemocuprein). J Biol Chem. 1969;244(22):6049-55.

26. Bradford MM. A rapid and sensitive method for the quantitation of microgram quantities of protein utilizing the principle of protein-dye binding. Anal Biochem. 1976;72(1-2):248-54.

27. Scheetz A, Nairn AC, Constantine-Paton M. NMDA receptor-mediated control of protein synthesis at developing synapses. Nat Neurosci. 2000;3(3):211.

28. Birla H, Rai SN, Singh SS, Zahra W, Rawat A, Tiwari N, et al. Tinospora cordifolia suppresses neuroinflammation in parkinsonian mouse model. NeuroMol Med. 2019;21:42-53.

29. Gorbatyuk OS, Li S, Sullivan LF, Chen W, Kondrikova G, Manfredsson FP, et al. The phosphorylation state of Ser-129 in human a-synuclein determines neurodegeneration in a rat model of Parkinson disease. Proc Nat Acad Sci. 2008;105(2):763-8.

30. Singh SS, Rai SN, Birla H, Zahra W, Kumar G, Gedda MR, et al. Effect of chlorogenic acid supplementation in MPTP-intoxicated mouse. Front Pharmacol. 2018;9:757.

31. Kulkarni S, Dhir A. Withania somnifera: an Indian ginseng. Prog Neuropsychopharmacol Biol Psychiatry. 2008;32(5):1093-105.

32. Bhatnagar M, Sharma D, Salvi M. Neuroprotective effects of Withania somnifera Dunal.: a possible mechanism. Neurochem Res. 2009:34(11):1975-83.

33. Prakash J, Chouhan S, Yadav SK, Westfall S, Rai SN, Singh SP. Withania somnifera alleviates parkinsonian phenotypes by inhibiting apoptotic pathways in dopaminergic neurons. Neurochem Res. 2014;39(12):2527-36.

34. Zhao J, Nakamura N, Hattori M, Kuboyama T, Tohda C, Komatsu K. Withanolide derivatives from the roots of Withania somnifera and their neurite outgrowth activities. Chem Pharm Bull. 2002;50(6):760-5.

35. Tohda C, Komatsu K, Kuboyama T. Scientific basis for the anti-dementia drugs of constituents from Ashwagandha (Withania somnifera). J Tad Med. 2005:22:176-82

36. Pati PK, Sharma M, Salar RK, Sharma A, Gupta A, Singh B. Studies on leaf spot disease of Withania somnifera and its impact on secondary metabolites. Indian J Microbiol. 2008;48(4):432-7.

37. Maitra R, Porter MA, Huang S, Gilmour BP. Inhibition of NFKB by the natural product Withaferin A in cellular models of cystic fibrosis inflammation. J Inflamm. 2009:6(1):15.

38. Narayan M, Zhang J, Braswell K, Gibson C, Zitnyar A, Lee DC, et al. Withaferin A regulates LRRK2 levels by interfering with the Hsp90-Cdc37 chaperone complex. Curr Aging Sci. 2015;8(3):259-65.

39. Yan Z, Guo R, Gan L, Lau WB, Cao X, Zhao J, et al. Withaferin A inhibits apoptosis via activated Akt-mediated inhibition of oxidative stress. Life Sci. 2018;211:91-101.

40. Banu MR, Ibrahim M, Prabhu K, Rajasankar S. Ameliorative effect of Withaferin A on ageing-mediated impairment in the dopamine system and its associated behavior of Wistar Albino Rat. Pharmacology. 2019;103(3-4):114-9.

41. Kumar A. Neuroinflammation over the life span and its impact on cognitive performance. Front Aging Neurosci. 2018;10:413.

42. Patel SB, Rao NJ, Hingorani LL. Safety assessment of Withania somnifera extract standardized for Withaferin A: acute and sub-acute toxicity study. J Ayurveda Integr Med. 2016;7(1):30-7. 
43. Sharada AC, Solomon FE, Devi PU. Toxicity of Withania somnifera root extract in rats and mice. Int J Pharmacogn. 1993;31(3):205-12.

44. Bittner GD, Yang CZ, Stoner MA. Estrogenic chemicals often leach from BPA-free plastic products that are replacements for BPA-containing polycarbonate products. Environ Health. 2014;13(1):41.

45. Brown JS Jr. Effects of bisphenol-A and other endocrine disruptors compared with abnormalities of schizophrenia: an endocrine-disruption theory of schizophrenia. Schizophr Bull. 2008;35(1):256-78.

46. Agarwal S, Tiwari SK, Seth B, Yadav A, Singh A, Mudawal A, et al. Activation of autophagic flux against xenoestrogen bisphenol-A induced hippocampal neurodegeneration via AMPK/mTOR pathways. J Biol Chem. 2015;290:21163-84.

47. Palanza P, Gioiosa L, vom Saal FS, Parmigiani S. Effects of developmental exposure to bisphenol A on brain and behavior in mice. Environ Res. 2008;108(2):150-7.

48. Kajta M, Wójtowicz AK. Impact of endocrine-disrupting chemicals on neural development and the onset of neurological disorders. Pharmacol Rep. 2013;65(6):1632-9.

49. Fujimoto T, Kubo K, Aou S. Prenatal exposure to bisphenol A impairs sexual differentiation of exploratory behavior and increases depressionlike behavior in rats. Brain Res. 2006;1068(1):49-55.

50. Xu X-H, Zhang J, Wang Y-M, Ye Y-P, Luo Q-Q. Perinatal exposure to bisphenol-A impairs learning-memory by concomitant down-regulation of $\mathrm{N}$-methyl-D-aspartate receptors of hippocampus in male offspring mice. Horm Behav. 2010;58(2):326-33.

51. Dudchenko PA. An overview of the tasks used to test working memory in rodents. Neurosci Biobehav Rev. 2004;28(7):699-709.

52. Kumar A, Foster TC. Alteration in NMDA receptor mediated glutamatergic neurotransmission in the hippocampus during senescence. Neurochem Res. 2019;44(1):38-48.

53. Foster TC, Kyritsopoulos C, Kumar A. Central role for NMDA receptors in redox mediated impairment of synaptic function during aging and Alzheimer's disease. Behav Brain Res. 2017;322(Pt B):223-32 (PubMed PMID: 27180169. Epub 2016/05/18. eng).

54. Berlett BS, Stadtman ER. Protein oxidation in aging, disease, and oxidative stress. J Biol Chem. 1997;272(33):20313-6.

55. Barnham KJ, Masters CL, Bush Al. Neurodegenerative diseases and oxidative stress. Nat Rev Drug Discov. 2004;3(3):205.
56. Muthuvel R, Venkataraman P, Krishnamoorthy G, Gunadharini D, Kanagaraj P, Stanley AJ, et al. Antioxidant effect of ascorbic acid on PCB (Aroclor 1254) induced oxidative stress in hypothalamus of albino rats. Clin Chim Acta. 2006;365(1-2):297-303.

57. Bindhumol V, Chitra K, Mathur P. Bisphenol A induces reactive oxygen species generation in the liver of male rats. Toxicology. 2003;188(2-3):117-24.

58. Chitra K, Latchoumycandane C, Mathur P. Induction of oxidative stress by bisphenol $\mathrm{A}$ in the epididymal sperm of rats. Toxicology. 2003;185(1-2):119-27.

59. Richter CA, Taylor JA, Ruhlen RL, Welshons WV, vom Saal FS. Estradiol and bisphenol A stimulate androgen receptor and estrogen receptor gene expression in fetal mouse prostate mesenchyme cells. Environ Health Perspect. 2007;115(6):902.

60. Aydoğan M, Korkmaz A, Barlas N, Kolankaya D. The effect of vitamin C on bisphenol A, nonylphenol and octylphenol induced brain damages of male rats. Toxicology. 2008;249(1):35-9.

61. Valko M, Leibfritz D, Moncol J, Cronin MT, Mazur M, Telser J. Free radicals and antioxidants in normal physiological functions and human disease. Int J Biochem Cell Biol. 2007;39(1):44-84.

62. RajaSankar S, Manivasagam T, Sankar V, Prakash S, Muthusamy R, Krishnamurti A, et al. Withania somnifera root extract improves catecholamines and physiological abnormalities seen in a Parkinson's disease model mouse. J Ethnopharmacol. 2009;125(3):369-73.

63. Lièvre $V$, Becuwe $P$, Bianchi $A$, Koziel V, Franck $P$, Schroeder $H$, et al. Free radical production and changes in superoxide dismutases associated with hypoxia/reoxygenation-induced apoptosis of embryonic rat forebrain neurons in culture. Free Radic Biol Med. 2000;29(12):1291-301.

64. Sehgal N, Gupta A, Valli RK, Joshi SD, Mills JT, Hamel E, et al. Withania somnifera reverses Alzheimer's disease pathology by enhancing lowdensity lipoprotein receptor-related protein in liver. Proc Natl Acad Sci. 2012;109(9):3510-5.

\section{Publisher's Note}

Springer Nature remains neutral with regard to jurisdictional claims in published maps and institutional affiliations.
Ready to submit your research? Choose BMC and benefit from:

- fast, convenient online submission

- thorough peer review by experienced researchers in your field

- rapid publication on acceptance

- support for research data, including large and complex data types

- gold Open Access which fosters wider collaboration and increased citations

- maximum visibility for your research: over $100 \mathrm{M}$ website views per year

At BMC, research is always in progress.

Learn more biomedcentral.com/submissions 